\title{
METODOLOGIAS ATIVAS NA EDUCAÇÃO DE JOVENS E ADULTOS : UM ESTUDO BIBLIOGRÁFICO
}

\author{
https://dx.doi.org/10.48097/2674-8673.2021n5p15
}

\author{
Joseli Soares da Silva ${ }^{1}$ \\ Vitória de Oliveira Silva ${ }^{2}$ \\ Fabiana Maria da Silva ${ }^{3}$
}

\begin{abstract}
RESUMO
O presente trabalho teve como objetivo principal analisar a relação entre metodologias ativas e o ensino e a aprendizagem de jovens e adultos. Esta pesquisa, de natureza qualitativa e do tipo exploratória, foi realizada a partir de estudo bibliográfico. O processo histórico da educação de jovens e adultos, desde sua constituição, e apesar de ser estruturado por lei, carece de estruturas e práticas pedagógicas mais específicas. Esse contexto coloca a importância das metodologias ativas como uma possibilidade de organização de aulas mais atraentes para os estudantes dessa modalidade e por romperem com um modelo tradicional de educação. As metodologias ativas são estratégias pedagógicas que colocam os estudantes como centro do processo educacional a partir de práticas inovadoras, capazes de promover a construção do conhecimento de maneira autônoma pelos estudantes. O presente estudo revelou que as metodologias ativas são extremamente pertinentes para os estudantes da EJA.
\end{abstract}

Palavras-chave: Ensino e Aprendizagem. Metodologias Ativas. Educação de Jovens e Adultos.

Data de submissão: $12 / 02 / 2021$

Data de aprovação: 26/03/2021

\begin{abstract}
The main objective of this work was to analyze the relationship between active methodologies and the teaching and learning of young people and adults. The present research, of qualitative nature and of the exploratory type, was carried out from a bibliographic study. The historical process of youth and adult education, since its constitution and despite being structured by law, lacks more specific pedagogical structures and practices. This context places the importance of active methodologies as a possibility of organizing more attractive classes for students of this modality and for breaking with a traditional model of education. Active methodologies are pedagogical strategies that place students at the center of the educational process based on innovative practices, capable of promoting the construction of knowledge autonomously by students. The present study revealed that the active methodologies are extremely relevant for EJA students.
\end{abstract}

Keywords: Teaching and Learning Process. Active Methodologies. Youth \& Adult education.

\footnotetext{
${ }^{1}$ Discente do Curso de Licenciatura em Pedagogia da Faculdade Metropolitana da Grande Recife.

E-mail: joselysol@hotmail.com

${ }^{2}$ Discente do Curso de Licenciatura em Pedagogia da Faculdade Metropolitana da Grande Recife. E-mail:

${ }^{3}$ Docente orientadora do Curso de Pedagogia da Faculdade Metropolitana da Grande Recife.

E-mail: fabiana.silva1@gmail.com
} 


\section{INTRODUÇÃO}

Esse artigo se propõe a estudar as metodologias ativas no contexto da Educação de Jovens e Adultos (EJA). Esta modalidade demanda estratégias de ensino diferenciadas, que considerem os educandos integralmente em seus contextos sociais. O desenrolar histórico da EJA nos mostra a necessidade de refletir sobre estratégias educacionais que ajudem os jovens e adultos no desenvolvimento de seus processos educacionais.

O debate sobre a EJA relaciona alguns fatores que fazem com que as pessoas não concluam a educação básica na idade certa. Fatores de ordem social e econômica são os mais citados, como por exemplo, a necessidade de trabalhar, as dificuldades de chegar até as escolas (realidade de muitos municípios brasileiros), e no caso das mulheres ainda tem a questão da gravidez na adolescência que acaba em muitos casos sendo um fator a mais para que as jovens não continuem seus estudos.

Quando essas pessoas decidem retomar seus estudos, muitas vezes se deparam com práticas infantilizadas que pouco as estimulam a dar continuidade aos estudos. É quando encontramos a questão da evasão dos estudantes e muitas vezes isso ocorre porque os alunos não encontram sentido nos conteúdos que lhes são apresentados. É necessário que se busque métodos inovadores que consigam trazer e manter esses alunos numa aprendizagem prazerosa. Pensando nessas dificuldades trazemos nesse de bate as metodologias ativas para o processo de aprendizagem da EJA.

O interesse nesse tema foi por conta de algumas pesquisas feitas em que foi possível observar uma grande evasão dos alunos nessa modalidade e isso nos fez buscar algo diferente e que incentivasse esses alunos a lutar por algo melhor, para que eles não viessem a sair das escolas.

A importância dessa pesquisa é trazer algo inovador que possa ajudar no processo de alfabetização de jovens e adultos, ajudando o docente a explorar as experiências dos alunos como ponto de partida para a construção do conhecimento.

\section{FUNDAMENTAÇÃO TEÓRICA}

Para compreender melhor nossa temática se faz necessário um breve resgate da história da educação de jovens e adultos no Brasil. A esse respeito, as pesquisas mostram que os primeiros anos da Educação de Jovens e Adultos no Brasil são influenciados pelo pensamento educacional colonial brasileiro, marcado pelo caráter restrito e limitado. 


\section{Desenvolvimento histórico da Educação de Jovens e Adultos}

A origem da EJA está demarcada basicamente por dois aspectos principais. O primeiro deles consiste na necessidade de jovens e adultos aprenderem a ler para exercer o seu direito de voto e o segundo aspecto está ligado à necessidade de atendimento mínimo às necessidades das elites brasileiras da década de 30, período de intensa industrialização, e por isso o interesse em formar a mão de obra minimamente "letrada". A EJA não surgiu com a perspectiva de promover o desenvolvimento dos sujeitos, mas sim a partir das necessidades ideológicas e materiais de determinada classe social brasileira. (XAVIER, 2019).

A partir da década de 1940 houve a fixação da Campanha da Educação de Adolescentes e Adultos (CEAA) que consistiu na primeira iniciativa pública de atendimento específico para esse segmento da educação. Mais precisamente em 1947, por emergência de alguns movimentos educacionais, essa campanha considerava a educação capaz de proporcionar a cada indivíduo, segundo suas capacidades, ferramentas fundamentais de domínio e acesso da cultura para melhor desenvolvimento. O propósito era promover educação à população analfabeta, tanto nas cidades quanto nas zonas rurais, para estimular o desenvolvimento econômico. (XAVIER, 2019).

Nessa perspectiva a educação popular, mais especificamente a alfabetização, ganha importância. É nesse contexto que se registra a criação de algumas iniciativas, cujo objetivo era transformar a realidade social das pessoas, como por exemplo: Movimento de Cultura Popular (MCP) de Pernambuco; em Natal, a campanha "de pé no chão também se aprende a ler"; e os Movimentos de Educação de Base (MEB/Centros Populares de Cultura-CPC's) que eram ligados à Igreja Católica.

No contexto dessas iniciativas destaca-se a política de educação do governo de João Goulart, que tinha como organizador o educador Paulo Freire, através do Plano Nacional de Alfabetização de Adultos (PNAA). Na década de 1960, Freire era o responsável pelo desenvolvimento do Programa Nacional de Alfabetização de Adultos (PNAA). Freire foi um grande influenciador das práticas públicas das ações educacionais voltadas para os jovens e adultos. Essa proposta favoreceu a inclusão econômica, social e política desses indivíduos. Assim, o ano de 1960 se torna um marco histórico para a educação desses jovens e adultos.

A Educação de Jovens e Adultos no Brasil veio, ao longo de décadas, ganhando alguma atenção das políticas educacionais. Atualmente, as Diretrizes Curriculares Nacionais abrangem os processos formativos da Educação de Jovens e Adultos como uma das modalidades da Educação Básica, nos termos da LDBN 9394/96. 


\section{Paulo Freire e as práticas pedagógicas na EJA}

No Brasil, pensar em educação de jovens e adultos é pensar em Paulo Freire. A educação que ele propôs estava voltada para a conscientização de vencer primeiro o analfabetismo político para que eles pudessem ler o mundo em sua volta, a partir das suas experiências, de suas culturas, e também de suas histórias.

Paulo Freire deixou contribuições valiosas para o processo de ensino-aprendizagem da Educação de Jovens e Adultos. Uma das contribuições mais importantes é retirar do professor o papel de detentor do saber e transferir para o aluno o papel de construtor e modificador de seus conhecimentos. Paulo Freire vivenciou a Educação de Jovens e Adultos de forma especial, pois não foi somente professor dessa modalidade de ensino, mas também um dos alunos integrantes desse tipo de educação. Essas experiências lhe permitiram analisar os tipos de métodos utilizados para esse público, a partir da sua própria experiência.

O método de ensino proposto por Paulo Freire (2004) trabalha em cima da cultura dos educandos. O saber ler e escrever está diretamente ligado à realidade cultural dos alunos. Se a aprendizagem se desse de forma distanciada da realidade de cada um deles, não faria sentido algum dominar a leitura e a escrita se não pudessem utilizá-la para fazer a leitura do seu mundo.

O que Paulo Freire (2005) mais defendia em suas teorias era a importância de resgatar a autoconfiança do educando. Sem acreditar em si mesmo e em sua capacidade, o educando não tem como libertar-se de sua condição social. A influência de Paulo Freire na modalidade da Educação de Jovens e Adultos é extremamente rica e positiva, devido à metodologia criada por ele, a qual permite a ligação do educando com o mundo em que vive, sem causar no aluno a sensação de que se encontra fora dele.

Encontramos em Freire uma grande defesa para as metodologias ativas, com sua afirmação de que na educação de adulto o que impulsiona a aprendizagem é a superação de desafios a partir da resolução de problemas e da construção do conhecimento novo a partir de conhecimentos e experiências de cada indivíduo. Dessa forma, a educação para Paulo Freire é promover a autoconfiança e autonomia na ação educativa. É nesse ponto que encontramos total relação com as metodologias ativas, pois essas estratégias buscam colocar o aluno no centro de sua própria aprendizagem e criar sua própria autonomia e autoconfiança.

\section{Explicando Metodologias Ativas}

As metodologias ativas surgiram como alternativa para a superação de uma tradição 
de aprendizagem passiva, uma vez que a apresentação oral dos conteúdos, por parte do professor, se constituía como única estratégia didática.

O conceito de metodologia ativa carrega as ideias de John Dewey sobre aluno ativo e construções do conhecimento em situações que superam a tradicional aula expositiva, cuja finalidade é a reprodução e a memorização de conteúdos de ensino. Dewey defende que os conteúdos ensinados em sala de aula são assimilados de forma mais fácil quando são associadas às tarefas realizadas pelos alunos. (PEREIRA et al., 2009).

Como explicam Pereira et al (2009), Dewey sempre defendeu a união da teoria e da prática. Sua contribuição para os processos educacionais dos adultos está justamente no sentido de valorizar a capacidade de pensamento e estimular o aluno adulto a pensar, principalmente em discussões coletivas, quando o conhecimento flui mais facilmente e assim é construído.

Um dos defensores das metodologias ativas aqui no Brasil foi Paulo Freire. O autor acredita que o sucesso na implementação das metodologias ativas vai muito além da sala de aula e requer um esforço global, além de um trabalho amplo que precisa abranger os alunos, professores, gestores e até a família.

As metodologias ativas são amplamente discutidas atualmente em detrimento do novo modelo de sociedade, que formata um novo modelo de estudantes, demandando uma nova configuração da educação e seus métodos. A sociedade está completamente influenciada pelo avanço tecnológico, que tem alterado muito a forma como as pessoas se relacionam, se comunicam e, sobretudo, como aprendem. O conhecimento não é mais exclusividade dos livros e do professor. Graças à tecnologia, as pessoas podem acessar incontáveis tipos de instruções, informações e conhecimentos pela internet. O saber não está mais centrado nas instituições formais de ensino.

Considerando esse cenário, entra em pauta a necessidade das escolas reformularem seus métodos de ensino para atender essa nova lógica de aprendizagem, esse novo perfil de estudantes. As metodologias ativas entram nesse debate, sobretudo, quando nos referimos a sujeitos que já construíram suas personalidades. Esses sujeitos já trazem suas histórias de vida, visões de mundo, construções políticas e sociais. As metodologias ativas funcionam como uma oportunidade de desenvolver aprendizagens, partindo dessas especificidades, de modo que esses estudantes sejam colocados como centro do processo, e sujeitos autônomos na construção do conhecimento.

As metodologias ativas são pertinentes no contexto da EJA porque consistem em uma nova concepção educacional em que os alunos são postos como os protagonistas ou principais 
agentes de seu aprendizado. Elas estimulam a crítica, enquanto os professores incentivam a reflexão.

Berbel (2011) discorre sobre o aspecto da motivação dos estudantes, extremamente importante no contexto da EJA. Para esse autor, a utilização de metodologias ativas favorece a motivação autônoma do aluno, extraindo o potencial do mesmo, despertando curiosidade para descobrir novos conceitos, inserindo o conhecimento teórico, possibilitando uma perspectiva própria e diferente do professor.

Dessa maneira, as metodologias ativas de ensino e aprendizagem podem constituir um caminho para a construção de uma maior participação do aluno, fazendo dele o principal agente da sua formação. Nessa perspectiva, percebemos as metodologias ativas como sendo um conjunto de atividades organizadas, que conta com a intenção educativa, em que os estudantes atuam como agentes ativos no processo de aprendizagem, através de estratégias pedagógicas que estimulam a produção de conhecimento.

As metodologias ativas são, portanto, interessantes para a modalidade EJA porque trazem grandes benefícios: adquirir maior autonomia, desenvolver a confiança, passar a enxergar o aprendizado como algo tranquilo, tornar-se apto a resolver problemas, tornar-se mais qualificado e valorizado, além de ser o protagonista do seu aprendizado. Para a instituição de ensino os benefícios se mostram principalmente pela maior satisfação dos alunos com o ambiente da sala de aula, melhor percepção dos alunos com a instituição, aumento do reconhecimento no mercado, além do aumento da atração, captação e retenção de alunos.

A aplicação de metodologias ativas de aprendizagem tem um papel importante para a educação de jovens e adultos, especialmente no Brasil, onde o setor necessita de transformações. Por isso, é preciso investir não somente em bons conteúdos, mas se faz necessário ter consciência de que aprimorar os procedimentos usados para educar é algo extremamente relevante.

A partir desses conceitos é possível compreender que a utilização das metodologias ativas nos processos de educação dos jovens e adultos é capaz de proporcionar aprendizagens significativas, justamente por, como já foi dito, colocar os indivíduos como sujeitos autônomos de seus processos de construção do conhecimento.

Nesse contexto, situamos o conceito de aprendizagens significativas como consequência da utilização de metodologias ativas. Para David Paul Ausubel (1918-2008), a aprendizagem significativa é elemento essencial ao processo de aquisição do conhecimento do aluno, fundamental para o novo papel do professor e a função social da escola. (MOREIRA, 
1982).

Segundo Moreira (1982), Ausubel elaborou a teoria da aprendizagem significativa e a definiu como o processo através do qual uma nova informação relaciona-se com um aspecto relevante da estrutura de conhecimento do indivíduo. Em linhas gerais, a aprendizagem significativa acontece quando o conhecimento novo se relaciona com a estrutura cognitiva do sujeito, com o que ele já sabe ou já construiu ao longo de suas experiências. O gráfico abaixo ilustra bem essa relação entre as metodologias ativas e as aprendizagens significativas:

Figura 1 - Metodologias ativas e aprendizagens significativas

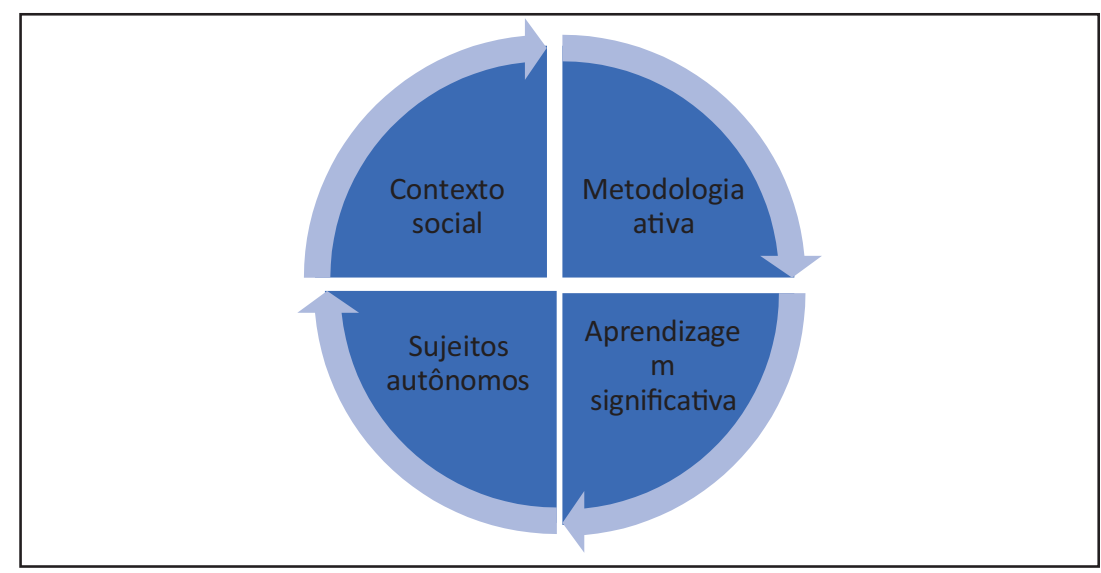

Fonte: as autoras

Assim, as metodologias ativas aplicadas no contexto da EJA são pertinentes por tudo que já foi discutido neste tópico, principalmente por proporcionarem aos estudantes desta modalidade aprendizagens significativas, construídas a partir da valorização de seus contextos sociais.

\section{Metodologias ativas que podem contribuir no processo de alfabetização da EJA}

O processo de ensino e aprendizagem de jovens e adultos necessita de estratégias específicas, pois, evidentemente, as formas como os jovens e adultos aprendem são diferentes das formas como as crianças constroem seu conhecimento, pois há muitas implicações e muita complexidade nesse contexto. Os processos de ensino precisam considerar as especificidades subjacentes à educação dos jovens e adultos. Martins (2013) nos chama atenção nesse aspecto quando afirma que

[...] ensinar já não é mais levar o conhecimento para a sala de aula e, sim, 
enriquecer e valorizar os conhecimentos dos estudantes, o que significa adequar as metodologias tradicionais aos conceitos de ANDRAGOGIA que levarão à construção coletiva dos conhecimentos a partir dos referenciais de vida deles, tornando o aprendizado mais agradável e contextualizado. (MARTINS, 2013, p. $145)$.

O aluno adulto busca na educação contínua a sua realização pessoal e profissional, aprendendo muito melhor quando o assunto tem valor de uso imediato. Quando os processos educacionais não são adaptados, por assim dizer, há um favorecimento da evasão, por parte dos estudantes. É necessário que tanto os currículos quanto os professores e metodologias dialoguem com o perfil desses estudantes. Conforme a visão de Pinto (2010):

É evidente que os problemas pedagógicos (a matéria a ensinar, os currículos, os métodos) correspondentes a cada faixa etária são distintos. Por isso a alfabetização do adulto é um processo pedagógico qualitativamente distinto do infantil (a não ser assim, cairíamos no erro da infantilização do adulto). (PINTO, 2010, p. 74).

Considerando as especificidades que o processo de ensino e aprendizagem dos adultos requer, a utilização de metodologias ativas pode proporcionar o pensamento crítico, boa comunicação, colaboração, e resolução de problemas com criatividade.

Destacaremos a seguir, de acordo com os estudos, as metodologias ativas mais apropriadas no processo de alfabetização de jovens e adultos: Aprendizagem Baseada em Problemas (PBL), Flipped Classroom (Sala de aula invertida) e Grupos Operatórios.

O primeiro exemplo de metodologias ativas indicada para o trabalho com a EJA é a Aprendizagem Baseada em Problemas (tradução para Problem Based Learning - PBL) que surgiu como ferramenta metodológica em 1969 na McMaster University Canadá para o estudo de medicina, mas é possível encontrar exemplos de implementação da PBL em todo o sistema educacional.

A Aprendizagem Baseada em Problemas - PBL é um método cuja característica está centrada no uso de problemas vivenciados e contextualizados ao conteúdo para encorajar os alunos a desenvolverem pensamento crítico e habilidades de solução de problemas e adquirirem conhecimento sobre os conceitos essenciais da área em questão. (RIBEIRO; MIZUKAMI, 2004).

A Aprendizagem Baseada em Problema (PBL) tem como propósito tornar o aluno capaz de construir o aprendizado conceitual, procedimental e atitudinal por meio de problemas propostos que o expõe a situações motivadoras e o prepara para o mundo do trabalho. Essa metodologia é bem interessante para a modalidade EJA, pois, enquanto a 
aprendizagem baseada em projetos exige que os alunos coloquem a "mão na massa", a aprendizagem baseada em problemas é focada na parte teórica da resolução de casos.

Para Ribeiro \& Mizukami (2004), o problema na PBL é um fim aberto, ou seja, não comporta uma única solução correta, mas uma (ou mais) melhor solução, dadas as restrições impostas pelo próprio problema ou pelo contexto de aprendizagem em que está inserido, tais como tempo, recursos, etc.

Este método, também conhecido como situação problema, parte de uma tarefa lançada com situações em tempo real em que o professor apresenta uma questão não tão fácil e nem tão difícil. Assim, o aluno obtém a capacidade de solucionar problemas. Essa metodologia leva o aluno a pensar criticamente, solucionar problemas e desenvolver seu trabalho em equipe. Sendo assim, a PBL é um dos métodos que, como pregava Paulo Freire, apresenta o aluno como protagonista do seu aprendizado e o professor como mediador do saber.

A Sala de Aula Invertida (Flipped Classroom) consiste em um método ativo bastante atual que tem por objetivo minimizar as aulas expositivas e ampliar/facilitar as possibilidades de aulas online. Seria muito interessante para a modalidade EJA, pois, nesse modelo, os alunos teriam acesso aos conteúdos de forma virtual, o que otimiza o tempo reservado aos estudos, uma necessidade tão pontual para os estudantes da EJA que muitas vezes precisam combinar estudo e trabalho.

A Sala de Aula Invertida é uma forma de evitar seguir o modelo tradicional expositivo de aula aumentando a participação e a produtividade. Ela faz parte da tendência do ensino híbrido, pois trabalha com a fusão de aulas presenciais e online, a partir das Tecnologias de Informação e Comunicação (TICS). Isso dá aos estudantes a possibilidade de solucionar as dúvidas no momento em que elas surgem, com a ajuda de seus colegas e do professor, promovendo um ambiente colaborativo de aprendizagem.

A abordagem requer que o aluno estude o tema em seu tempo, antes da aula presencial, para que ele seja capaz de acompanhar as discussões e possa alcançar um maior aproveitamento das informações. O método da Sala de Aula Invertida é apresentado como uma proposta de repensar os processos de ensino e aprendizagem no espaço onde ocorrem, objetivando a inserção de metodologias e tecnologias educacionais, no sentido de otimizar as etapas de transmissão e de assimilação dos conhecimentos. (SCHNEIDERS, 2018).

A Sala de Aula Invertida consiste na inversão do modelo tradicional, no qual o professor passa o conteúdo e em seguida, em casa, o aluno tenta resolver os exercícios e identifica suas dúvidas. A intenção é que os estudantes da EJA tenham o primeiro contato com o conteúdo antes de chegarem à escola, para então serem auxiliados pelo educador em 
relação às dúvidas e à resolução de questões.

Outro exemplo de metodologia ativa defendida para a EJA é a metodologia baseada em Grupos Operativos. Ela coloca em evidência a possibilidade de uma nova elaboração de conhecimento, de integração e de questionamentos acerca de si e dos outros. A aprendizagem é um processo contínuo em que comunicação e interação são indissociáveis, na medida em que aprendemos a partir da relação com os outros. (MORAN; BACICH, 2018).

Em outras palavras, metodologias baseadas em Grupos Operatórios ajudam o aluno a interagir com os colegas, compartilhando conhecimento e trabalhando com um pensamento crítico, pois a constituição do sujeito é marcada por uma contradição interna, onde ele precisa, para satisfazer as suas necessidades, entrar em contato com o outro, vincular-se a ele e interagir com o mundo.

Essa metodologia é indicada para a EJA porque pressupõe a possibilidade de ser uma forma de aprendizado centrada no aluno, que é uma prerrogativa da aprendizagem ativa, ainda com o viés de ser uma estratégia metodológica que envolve o trabalho em grupo na busca da formação crítica.

Alguns autores falam que o grupo é o contexto onde se pode reconstruir e criar significados, vivenciar questões através da troca de informações, do insight, da identificação e outros processos. O grupo funciona como um campo de referências cognitivas e afetivas, em que o sujeito se integra e se reconhece, podendo tanto bloquear quanto estimular processos criativos e críticos.

No contexto desses exemplos de metodologias ativas para o trabalho na EJA, é importante pensar o fazer pedagógico nessa perspectiva, e isso requer também destacar a necessidade dos processos de formação de professores contemplarem também as necessidades desta modalidade. Não basta dispor de uma série de estratégias específicas para a EJA, sem que os professores saibam como colocá-las em prática. No entanto, o docente que aplicar as metodologias ativas terá como resultado a promoção do educando reflexivo, autônomo, crítico e com conhecimento baseado em uma metodologia que o torna corresponsável pelo seu próprio conhecimento.

\section{METODOLOGIA}

A presente pesquisa possui natureza qualitativa, que nos parece mais indicada para as pesquisas em educação, já que é baseada no caráter subjetivo, ou seja, seu resultado não mostra números concretos, e sim narrativas, ideias e experiências individuais dos 
participantes.

Optamos por realizar uma pesquisa exploratória, a partir de levantamento bibliográfico como técnica de coleta de dados. Os materiais utilizados nessa pesquisa foram sete livros e cinco artigos científicos pesquisados nas plataformas da Scielo e no Google Acadêmico.

Assim, foi realizado um levantamento bibliográfico desenvolvido com base em material já elaborado acerca da temática de metodologias ativas no processo de ensino e aprendizagem na educação de jovens e adultos, constituído por livros e artigos científicos. A partir dos dados obtidos, realizou-se a análise e interpretação das informações, mesclando-as de maneira a conseguir uma maior compreensão e aprofundamento sobre o tema abordado.

\section{RESULTADOS}

Ao analisar a história da educação de jovens e adultos foi possível descobrir que esta modalidade de ensino é amparada por lei e tem como objetivo atender os indivíduos que não tiveram acesso, por algum motivo, ao ensino regular na idade apropriada. A EJA visa escolarizar e socializar esses alunos, a partir do princípio da igualdade do direito à educação. O desenvolvimento histórico da EJA também revelou que esta modalidade surgiu a partir de interesses ideológicos, no sentido de formar uma classe trabalhadora minimamente letrada, e que pudesse dar conta do desenvolvimento da elite brasileira.

A Educação de Jovens e Adultos teve algumas conquistas ao longo dos anos, e uma delas foi o fato desta modalidade ter sido incluída no Fundo de Manutenção e Desenvolvimento da Educação Básica e de Valorização dos Profissionais da Educação (FUNDEB), em 2007. Esse fato ajudou muito nas questões básicas, como reservas e recursos para a educação de jovens e adultos, por exemplo.

O objetivo dessa modalidade de ensino é permitir que pessoas adultas, que não tiveram a oportunidade de frequentar a escola na idade certa, possam retomar seus estudos e recuperar o tempo perdido. Nas pesquisas realizadas observamos uma carência muito grande nessa modalidade, além de grande evasão nas escolas devido a inúmeros motivos, com destaque para as metodologias aplicadas em sala de aula, que muitas vezes não são pensadas para esse perfil de estudantes.

A pesquisa nos revelou que as metodologias ativas são capazes de suprir essa falta de especificidade que acontece na EJA, uma vez que podem ajudar os alunos a terem mais interesse pelas aulas, saindo da perspectiva tradicional, em que o professor é o protagonista do processo. Com a utilização de metodologias ativas o professor passa a ser o mediador do processo e o aluno passa a ser o protagonista do seu próprio aprendizado, sendo um aluno 
mais crítico e reflexivo.

Com o estudo dos conceitos de metodologias ativas o presente artigo evidenciou que, como o professor tem um papel crucial na formação dos estudantes, o trabalho pedagógico do docente é crucial para que a utilização das metodologias ativas proporcione aprendizagens significativas.

Assim, observamos que o docente precisa, além de compreender as necessidades da prática pedagógica na EJA, saber qual o tipo de metodologia que mais pode corresponder com o planejamento da aula e com o perfil daquele grupo de estudantes.

Não basta saber que as metodologias ativas são importantes. É fundamental o domínio dessas estratégias por parte docente, especialmente no contexto atual, mediado pelas tecnologias.

Sobre esse papel fundamental dos professores da EJA em relação ao domínio das metodologias ativas, buscamos apresentar alguns exemplos que podem ser utilizados. A pesquisa nos conduziu para os seguintes exemplos: Aprendizagem Baseada em Problemas (PBL), Sala de Aula Invertida, e Grupos Operatórios. As referidas metodologias são interessantes para a EJA porque estão centradas nos estudantes e em seus contextos, por permitirem a utilização de tecnologias (importante ferramenta para a interação no mundo contemporâneo), pela promoção da interação entre os sujeitos, e da autorresponsabilidade com os estudos.

Assim, cabe aos profissionais da EJA um aperfeiçoamento das suas técnicas pedagógicas para que utilizem metodologias ativas de ensino que garantam a permanência desses educandos na escola, proporcionando-lhes um ensino significativo, que os levem à análise crítica dos fatos abordados em sala de aula e do seu meio social.

\section{CONSIDERAÇÕES FINAIS}

Por meio desta pesquisa foi possível constatar que as metodologias ativas podem proporcionar melhores experiências educativas nesta modalidade de educação, pois valorizam os contextos dos estudantes, colocados como o centro do processo, ou seja, a utilização de metodologias ativas na EJA é uma estratégia pedagógica importante para tornar a referida modalidade mais interessante, o que pode contribuir com a diminuição dos números de evasão.

Consideramos também que não basta simplesmente utilizar aulas "diferentes" e afirmar que está aplicando uma metodologia ativa. Os educadores que estão na EJA precisam refletir as especificidades desta modalidade, principalmente nos seus planejamentos diários e 
projetos pedagógicos, assim como também é emergente que essa reflexão perpasse as políticas públicas.

Por fim, ponderamos que a temática tratada neste breve estudo é fundamental para o debate da educação, pois revelou importantes reflexões necessárias para o melhoramento das práticas pedagógicas no contexto da EJA, uma modalidade tão importante para fortalecer a democratização da educação com qualidade no Brasil. Ressaltamos ainda que, dada essa importância à temática, a discussão deve ser ampliada em novas pesquisas acadêmicas para que seja explorada a partir de perspectivas diferentes.

\section{REFERÊNCIAS}

BARBOSA, E. F.; MOURA, D. G. Metodologias ativas de aprendizagem na Educação Profissional e Tecnológica. Boletim Técnico Senac. Rio de Janeiro, 39(2), 48-67, 2013.

BECK, C. Metodologias Ativas: conceito e aplicação. ANDRAGOGIA Brasil. 2018. Disponível em: https://andragogiabrasil.com.br/metodologias-ativas/. Acesso em: 18 jun. 2020.

BERBEL, N. A. N. As metodologias ativas e a promoção da autonomia de estudantes. Semina: Ciências Sociais e Humanas, Londrina, v. 32, n. 1, p. 25-40, Jan/Jun, 2011.

BRAGA, Fabiana Marini; FERNANDES, Jarina Rodrigues. Educação de Jovens e Adultos: contribuições de artigos em periódicos brasileiros indexados na base SCIELO (2010-2014). Cad. CEDES, vol. 35, n. 96, Campinas: maio/ago. 2015. https://doi.org/10.1590/CC010132622015723757.

BRASIL. Lei de Diretrizes e Bases da Educação Nacional - LDB. Lei n. 9.424, de 24 de dezembro de 1996.

COSTA, Martins Cabral. (org.) Metodologias ativas: métodos e práticas para o século XXI. Quirinópolis, GO: Editora IGM, 2020.

FREIRE, Paulo. Pedagogia da autonomia: saberes necessários à prática educativa. São Paulo: Paz e Terra, 2004.

FREIRE, Paulo. Pedagogia do oprimido. Rio de Janeiro: Paz e Terra, 2005.

MARTINS, R. M. K. Pedagogia e andragogia na construção da educação de jovens e adultos. Rev. Ed. Popular, Uberlândia, v. 12, n. 1, p. 143-153, jan./jun. 2013. 
MORAN, J.; BACICH, L. Metodologias ativas para uma educação inovadora: uma abordagem teórico-prática. Porto Alegre: Penso, 2018.

MOREIRA, Marco Antônio; ELCIE, F. S. M. Aprendizagem significativa: a teoria de David Ausubel. São Paulo: Editora Moraes, 1982.

PAIVA, M. R. F. Metodologias Ativas de Ensino-Aprendizagem. 2016. Disponível em: http://www.scielo.br/pdf/spp/v14n2/9782.pdf. Acesso em: 25 jun. 2020.

PEREIRA, E. A; MARTINS, J. R.; ALVES, V. S.; DELGADO, E. I. A contribuição de John Dewey para a Educação. Revista Eletrônica de Educação. São Carlos, SP: UFSCar, v.3, no. 1, p. 154-161, mai. 2009. Disponível em: http://www.reveduc.ufscar.br/index.php/reveduc/article/view/38/37. Acesso em: 20 jun. 2020.

PINTO, Álvaro Vieira. Sete lições sobre educação de adultos. 16. ed. São Paulo: Cortez, 2010.

RIBEIRO, Luis Roberto de Camargo; MIZUKAMI, Maria da Graça Nicoletti. Uma Implementação da Aprendizagem Baseada em Problemas (PBL) na Pós-Graduação em Engenharia sob a Ótica dos Alunos. Revista UEL, Londrina, v. 25, p. 89-102, set. 2004.

SCHNEIDERS, Luís Antônio. O método da sala de aula invertida (flipped classroom). Lajeado-RS: Ed. UNIVAT ES, 2018.

XAVIER, C. F. História e Historiografia da Educação de Jovens e Adultos no Brasil inteligibilidades, apagamentos, necessidades, possibilidades. Revista Brasileira de História da Educação, v. 19, e068. 2019. Universidade Federal de Alfenas. DOI: https://doi.org/10.4025/rbhe.v19.2019.e068. 